\title{
Manufacturing best practices in Malaysian small and medium enterprises (SMEs)
}

\begin{abstract}
Purpose: The purpose of this paper is to investigate the current level of best manufacturing practices in Malaysian ISO 9000 certified small and medium enterprises (SMEs).

Design/methodology/approach: The authors conducted a survey on 270 ISO 9000 certified manufacturing SMEs. Based on an extensive search of literature on performance requirements, eight areas were identified. Thus, the questionnaire was designed consisting of the eight areas which are management, human resources development (HRD), technology and product innovation, marketing strategy, quality, production process, supply chain management (SCM) and customer focus. Data were analysed using the SPSS software.

Findings: The results showed that among the eight areas, customer focus is the most implemented area with the highest mean of 4.16, followed by quality (3.92), management (3.78), SCM (3.56), HRD (3.27), marketing strategy (3.05), production process (3.02) and technology and product innovation with a score of 2.95. The results showed that the level of best manufacturing practices can be improved further, especially in the area of technology and product innovation.
\end{abstract}

Research limitations/implications: Only the companies certified with ISO 9000 were selected. The questionnaire only covered eight areas of benchmarking and was analysed using descriptive statistics.

Practical implications: The paper provides knowledge in assisting the SMEs to identify the areas that they have to improve to achieve best manufacturing practices.

Originality/value: This is the first attempt to benchmark best manufacturing practices in some Malaysian ISO 9000 certified SMEs. The paper provides some useful insights and can help Malaysian manufacturing companies to implement best practices and benchmarking to improve their practices.

Keyword: Benchmarking; ISO 9000 series; Malaysia; Manufacturing systems; Small to medium-sized enterprises 